\title{
Rural-Urban Continuum Codes 2013
}

National Cancer Institute

\section{Source}

National Cancer Institute. Rural-Urban Continuum Codes 2013. NCI Thesaurus. Code C160901.

Codes published by the Office of Management and Budget (OMB) in 2013 that separate counties into four metropolitan and six non-metropolitan categories based on the size their populations and form a classification scheme that disting uishes metropolitan counties by size and non-metropolitan counties by degree of urbanization and proximity to metro areas. 